\title{
EXCESSIVE DAYTIME SLEEPINESS IN MEDICAL STUDENTS
}

\author{
Deepa Rajendran ${ }^{1}$, Vinod P. B2, Karthika M3, Prathibha M. T4
}

${ }^{1}$ Assistant Professor, Department of Physiology, Government T. D. Medical College, Alappuzha.

${ }^{2}$ Associate Professor, Department of Surgery, Government T. D. Medical College, Alappuzha.

${ }^{3}$ Associate Professor, Department of Community Medicine, Government T. D. Medical College, Alappuzha.

${ }^{4}$ Assistant Professor, Department of Community Medicine, Travancore Medical College, Kollam.

\section{BACKGROUND}

ABSTRACT

Excessive daytime sleepiness (EDS) is a symptom, which has many adverse consequences. Only limited information is available on the prevalence of excessive daytime sleepiness in medical students from Kerala. This study aims at estimating the prevalence of EDS among medical students in a Government Medical College in Kerala.

\section{MATERIALS AND METHODS}

A questionnaire based study was conducted on medical students of a Government Medical College in Kerala. EDS was diagnosed using Epworth Sleepiness Scale.

\section{RESULTS}

Study population consisted of 349 students. Prevalence of EDS was 25.5\%. There was no gender difference in prevalence of EDS.

\section{CONCLUSION}

Prevalence of EDS is high in medical students in our institution.

\section{KEYWORDS}

Excessive Daytime Sleepiness, Epworth Sleepiness Scale (ESS), Medical Students.

HOW TO CITE THIS ARTICLE: Rajendran D, Vinod PB, Karthika M, et al. Excessive daytime sleepiness in medical students. J. Evolution Med. Dent. Sci. 2018;7(06):747-749, DOI: 10.14260/jemds/2018/169

\section{BACKGROUND}

Excessive daytime sleepiness (EDS) is sleepiness in a situation when an individual would be expected to be awake and alert.[1] The person feels difficulty in maintaining sleep during the major wake period of the day and he may unintendedly lapse into drowsiness or sleep. ${ }^{[2]}$ Though sleep deprivation is the most common cause of EDS, many neuropsychiatric and medical illnesses also can present with EDS.[3] Prevalence of EDS was reported to be $15 \%$ - 26\% in adult population. ${ }^{[4]}$ Medical students are especially vulnerable to EDS due to the huge academic burden they are subjected to.[5] Many studies have assessed the prevalence of EDS in medical students. In spite of extensive literature search, we could not find a local study assessing the prevalence of EDS in medical students. This study is conducted to assess the prevalence of EDS in medical students of Government Medical College in Kerala.

\section{MATERIALS AND METHODS}

The study was performed among medical students in a Government Medical College in Kerala, India. This was a questionnaire based study. The study was approved by Institutional Ethics Committee. The study procedure was explained to the students and those giving written consent were included in the study.

'Financial or Other Competing Interest': None.

Submission 17-01-2018, Peer Review 29-01-2018,

Acceptance 31-01-2018, Published 05-02-2018.

Corresponding Author:

Dr. Vinod P. B,

Associate Professor, Department of Surgery,

Government T. D. Medical College, Alappuzha.

E-mail: pbdrvinod@gmail.com

DOI: $10.14260 /$ jemds $/ 2018 / 169$

\section{(c) $(1)$}

"Epworth sleepiness scale" (ESS) was used to diagnose EDS. It is a standard questionnaire introduced by Dr. Murray Johns of Epworth Hospital in 1991; Melbourne. ESS consists of 8 questions. The participant has to rate his/ her chance of falling asleep in eight different situations on a 4-point scale from 0 - 3. 0- signifies no dozing, 1- mild chance of dozing, 2moderate chance of dozing and 3- high chance of dozing. Total score can range from 0 - 24. The participants were scored as having EDS if the total score is $>11 .[6]$

\section{Analysis ${ }^{[5]}$ and Results}

All data were coded, entered and analysed using the Statistical Package for Social Sciences Program (SPSS), version 16.

\section{Day time sleepiness}

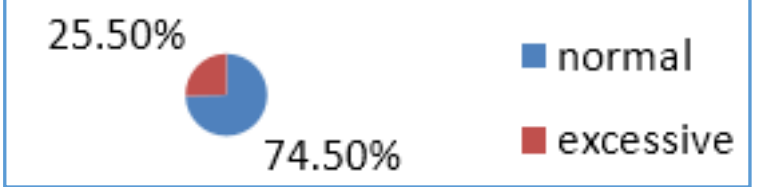

Figure 1. Overall Prevalence of EDS

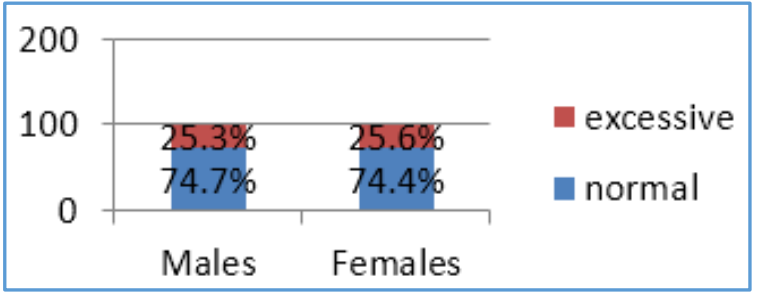

Figure 2. Gender Wise distribution of EDS 


\begin{tabular}{|c|c|c|c|c|}
\hline Situations & $\begin{array}{c}\text { No Dozing } \\
\text { Number } \\
(\%)\end{array}$ & $\begin{array}{c}\text { Mild } \\
\text { Dozing } \\
\text { Number } \\
(\%)\end{array}$ & $\begin{array}{c}\text { Moderate } \\
\text { Dozing } \\
\text { Number } \\
\text { (\%) }\end{array}$ & $\begin{array}{c}\text { Severe } \\
\text { Dozing } \\
\text { Number } \\
(\%)\end{array}$ \\
\hline $\begin{array}{l}\text { Sitting and } \\
\text { reading }\end{array}$ & $\begin{array}{c}26 \\
(7.4 \%)\end{array}$ & $\begin{array}{c}138 \\
(39.5 \%)\end{array}$ & $\begin{array}{c}132 \\
(37.8 \%)\end{array}$ & $\begin{array}{c}53 \\
(15.2 \%)\end{array}$ \\
\hline $\begin{array}{c}\text { Watching } \\
\text { TV }\end{array}$ & $\begin{array}{c}187 \\
(53.6 \%)\end{array}$ & $\begin{array}{c}132 \\
(37.8 \%)\end{array}$ & $\begin{array}{c}28 \\
(8.0 \%)\end{array}$ & $\begin{array}{c}2 \\
(0.6 \%)\end{array}$ \\
\hline $\begin{array}{c}\text { Sitting } \\
\text { inactive in } \\
\text { a public } \\
\text { place }\end{array}$ & $\begin{array}{c}103 \\
(29.5 \%)\end{array}$ & $\begin{array}{c}145 \\
(41.5 \%)\end{array}$ & $\begin{array}{c}79 \\
(22.6 \%)\end{array}$ & $\begin{array}{c}22 \\
(6.3 \%)\end{array}$ \\
\hline $\begin{array}{c}\text { As a } \\
\text { passenger } \\
\text { in } \\
\text { car for an } \\
\text { hour } \\
\end{array}$ & $\begin{array}{c}64 \\
(18.3 \%)\end{array}$ & $\begin{array}{c}116 \\
(33.2 \%)\end{array}$ & $\begin{array}{c}91 \\
(26.1 \%)\end{array}$ & $\begin{array}{c}78 \\
(22.3 \%)\end{array}$ \\
\hline $\begin{array}{l}\text { Lying down } \\
\text { in } \\
\text { afternoon }\end{array}$ & $\begin{array}{c}14 \\
(4.0 \%)\end{array}$ & $\begin{array}{c}36 \\
(10.3 \%)\end{array}$ & $\begin{array}{c}111 \\
(31.8 \%)\end{array}$ & $\begin{array}{c}188 \\
(53.9 \%)\end{array}$ \\
\hline $\begin{array}{l}\text { Sitting and } \\
\text { talking } \\
\text { to someone }\end{array}$ & $\begin{array}{c}301 \\
(86.2 \%)\end{array}$ & $\begin{array}{c}39 \\
(11.2 \%)\end{array}$ & $\begin{array}{c}7 \\
(2.0 \%)\end{array}$ & $\begin{array}{c}2 \\
(0.6 \%)\end{array}$ \\
\hline $\begin{array}{c}\text { Sitting } \\
\text { quietly } \\
\text { after lunch } \\
\text { without } \\
\text { alcohol }\end{array}$ & $\begin{array}{c}31 \\
(8.9 \%)\end{array}$ & $\begin{array}{c}135 \\
(38.7 \%)\end{array}$ & $\begin{array}{c}105 \\
(30.1 \%)\end{array}$ & $\begin{array}{c}78 \\
(22.3 \%)\end{array}$ \\
\hline $\begin{array}{l}\text { In car while } \\
\text { stopping in } \\
\text { traffic } \\
\text { for few } \\
\text { minutes }\end{array}$ & $\begin{array}{c}261 \\
(74.8 \%)\end{array}$ & $\begin{array}{c}61 \\
(17.5 \%)\end{array}$ & $\begin{array}{c}17 \\
(4.9 \%)\end{array}$ & $\begin{array}{c}10 \\
(2.9 \%)\end{array}$ \\
\hline
\end{tabular}

Study population consisted of 349 students (male $=146$, female $=203$ ) with age range of $19-28.25 .5 \%$ of study population had EDS (total ESS score > 11). Prevalence in males and females were $25.3 \%$ and $25.6 \%$ respectively.

\section{Dozing Pattern in Different Situations (\%)}

- $\quad$ Sitting and reading- majority students (39.5\%) reported mild dozing and least number (7.4\%) reported no dozing.

- Watching TV- majority students (53.6\%) reported no dozing and least number $(0.6 \%)$ reported severe dozing.

- Sitting inactive in a public place- majority students reported $(41.5 \%)$ mild dozing and least number $(6.3 \%)$ reported severe dozing.

- As a passenger in car for an hour- majority students (33.2\%) reported mild dozing and least number (18\%) reported no dozing.

- $\quad$ Lying down in the afternoon- majority students (53.9\%) reported high dozing and least number (4\%) reported no dozing.

- Sitting and talking to someone- majority students $(86.2 \%)$ reported no dozing and least number $(2.0 \%)$ reported moderate dozing.

- Sitting quietly after lunch without alcohol- majority students (38.7\%) reported slight dozing and least number $(8.9 \%)$ reported no dozing.

- In car while stopping in traffic for few minutes- majority students $(74.8 \%)$ reported no dozing and least number (2.9\%) reported severe dozing.

\section{DISCUSSION}

The overall prevalence EDS in our study was 25.5\%. This result is consistent with study conducted among medical students of Madha Medical College and Research Institute, Chennai where the prevalence of EDS was $30.57 \% .{ }^{[5]}$ The result is also consistent with the prevalence in Brazilian medical students (39.5\%) ${ }^{[5,7]}$ and Malaysian medical students (35.5\%).[5,8] But our result is on the higher side when compared to prevalence reported by Giri et al, $17.3 \% .{ }^{[6]}$ In another study in first year medical students, only $10 \%$ students demonstrated increased daytime sleepiness. ${ }^{[9]}$

Analysis of gender wise prevalence of EDS revealed almost equal prevalence in male $(25.3 \%)$ and female students (25.6\%). But Srihari et al reported higher prevalence of EDS in males than females.[5] A study from Saudi Arabia reported that excessive day time sleepiness is more common in female students.[10]

Insufficient sleep is probably the most common cause of daytime sleepiness.[3] Sleep deprivation is a common finding in medical students.[11] A study in Chinese medical students reported that more than $90 \%$ of the students experienced excessive sleepiness in class.[11] In a study from Hong Kong about $70 \%$ of medical students reported sleep deprivation. ${ }^{[2]}$ The average sleep duration of the students in their study was only 6.6 hours. It is thought that a young adult requires about 8 hours sleep.[11] In a study from Uttar Pradesh in first year medical students, the mean total sleep time was $4.6 \pm 1.6$ hrs. ${ }^{[9]}$ In this study, $60 \%$ of students scored PSQI was $>5$ indicating poor sleep quality. A study found that medical students had worse sleep quality and associated poorer quality of life compared to law and economic students.[12]

Sleep deprivation can be due to poor sleep behaviours. Those behaviours which improve the quantity and quality of sleep is called sleep hygiene.[13] Poor sleep behaviours include irregular sleep schedules, frequent or prolonged daytime naps, excessive alcohol consumption before bedtime and staying on one's bed for non-sleep-related activities.[13]

$\mathrm{Ng}$ et al (2009), Sweileh et al (2011) reported that the sleep-wake cycle of medical students is characterised by insufficient sleep duration, delayed sleep onset and occurrence of napping episodes during the day.[14] Irregular bedtime, early waking up and excessive intake of caffeine products and stimulants among medical students was also reported among medical students.[15] A study from Pravara Institute of Medical Sciences reported that excessive coffee intake, alcohol abuse, smoking and use of mobile phones/laptop were the factors which adversely affected sleep in medical students.[6] In a study done in Pakistan, the most common cause of sleep deprivation was watching television and listening to music. ${ }^{[16]} \mathrm{A}$ study in Nepal reported that $31.5 \%$ of medical students suffered from sleep deprivation due to late night internet surfing.[11] In our study, 59.9\% students reported using internet late at night.

Analysis of dozing pattern in different situations revealed results similar to that reported by Srihari et al. While watching TV and when sitting and talking to someone, no dozing was reported by majority of students. But dozing was reported in states like lying down in the afternoon, sitting quietly after lunch or in a public place and being a passenger in car for an hour. 
Sleep disorders are another cause of sleepiness. A study by Gaultney et al[2] among college students reported that $27 \%$ were at risk for at least one sleep disorder. The reported prevalence in their study was obstructive sleep apnoea (4\%), insomnia (12\%), restless legs disorder and periodic limb movement disorder (8\%), circadian rhythm sleep disorders (7\%) and hypersomnia (4\%). One study evaluated risk factors for sleep apnoea among Pakistani medical students and reported that $27 \%$ of males and $12 \%$ of females had disruptive snoring. [11] Foley et al (1995) reported insomnia symptoms in $28 \%$ of medical students.[10] Eller et al (2006) has reported insomnia complaints as an early marker of psychiatric disorders such as anxiety and depression.[10]

Day time sleepiness can adversely affect the work performance of individuals.[17] A study by Powell et al (1999) reported that decreased performance due to sleepiness may be worse than that due to alcohol intoxication. [3] Problems with concentration, memory and mood are also demonstrated with EDS.[3] $>$ 50,000 motor vehicle accidents each year in the United States are attributed to sleepy driving.[3] In a study conducted in undergraduate students by Taylor DJ et al 16\% reported falling asleep while driving and $2 \%$ reported a motor vehicle accident due to sleepiness.[11] Presence of sleep disorders may affect academic performance of students. Ficker JH et al compared examination results of snoring and non-snoring medical students and found that frequent snorers failed more frequently in their Internal Medicine examination than occasional snorers and nonsnorers. ${ }^{[2]}$ Sleep disorders in long term can lead to metabolic disorders, obesity, cardiovascular disorders, hypertension, acute coronary syndrome, stroke.[17]

Several studies have been conducted to assess the awareness of medical students about sleep. Most of them revealed that knowledge of medical students about sleep is poor and they had many false conceptions about sleep.[11] Students should be informed about the consequences of EDS and urged to follow healthy sleep practices.

Limitations of our study include small sample size and the questionnaire based data.

\section{CONCLUSION}

High prevalence of EDS in our study is a matter of concern. Students with EDS is to be evaluated further for the correlates of EDS.

\section{REFERENCES}

[1] Johns MW. What is excessive daytime sleepiness? Chapter 2. In: Fulke P, Vaughan S. eds. Sleep deprivation: causes, effects and treatment. Hauppauge/New York: Nova Sciences Publishers Inc., 2009:1-37.

[2] Hershner SD, Chervin RD. Causes and consequences of sleepiness among college students. Nature and Science of Sleep 2014;6:73-84.
[3] Guilleminault C, Brooks SN. Excessive daytime sleepiness: a challenge for the practising neurologist. Brain 2001;124(Pt 8):1482-91.

[4] Joo S, Shin C, Kim J, et al. Prevalence and correlates of excessive daytime sleepiness in high school students in Korea. Psychiatry and Clinical Neurosciences 2005;59(4):433-40.

[5] Ramamoorthy S, Mohandas M, Sembulingam P, et al. Prevalence of excessive day time sleepiness (EDS) among medical students. WJPR 2014;3(4):1819-26.

[6] Giri PA, Baviskar MP, Phalke DB. Study of sleep habits and sleep problems among medical students of Pravara Institute of Medical Sciences Loni, Western Maharashtra, India. Annals of Medical And Health Sciences Research 2013;3(1):51-4.

[7] Rodrigues RN, Viegas CA, Silva AEAA, et al. Daytime sleepiness and academic performance in medical students. Arq Neuropsiquiatr 2002;60(1):6-11.

[8] Zailinawati AH, Teng CL, Chung YC, et al. Daytime sleepiness and sleep quality among Malaysian medical students. Med J Malaysia 2009;64(2):108-10.

[9] Goel N, Malhotra V, Tripathi Y. Sleep habits among first year medical students. J Evolution Med Dent Sci 2016;5(38):2276-8.

[10] Abdulghani HM, Alrowais NA, Bin-Saad NS, et al. Sleep disorder among medical students: relationship to their academic performance. Medical Teacher 2012;34(Suppl 1):S37-41.

[11] Azad MC, Fraser K, Rumana N, et al. Sleep disturbances among medical students: a global perspective. Journal of Clinical Sleep Medicine 2015;11(1):69-74.

[12] Preišegolavičiūtė E, Leskauskas D, Adomaitienė V. Associations of quality of sleep with lifestyle factors and profile of studies among Lithuanian students. Medicina (Kaunas) 2010;46(7):482-9.

[13] Brick CA, Seely DL, Palermo TM. Association between sleep hygiene and sleep quality in medical students. Behavioral Sleep Medicine 2010;8(2):113-21.

[14] Lima PF, Medeiros AL, Araujo JF. Sleep-wake pattern of medical students: early versus late class starting time. Brazilian Journal of Medical and Biological Research 2002;35(11):1373-7.

[15] Al-Zahrani JM, Aldossari KK, Abdulmajeed I, et al. Daytime sleepiness and academic performance among Arab medical students. J of Thoracic Disease 2016;8(2):AB006.

[16] Qidwai W, Ishaque S, Shah S, et al. Adolescent lifestyle and behaviour: a survey from a developing country. PLoS One 2010;5(9):e12914.

[17] Kaur G, Singh A. Excessive daytime sleepiness and its pattern among Indian college students. Sleep Medicine 2017;29:23-8. 